\title{
Article \\ Whole-Brain Radiotherapy vs. Localized Radiotherapy after Resection of Brain Metastases in the Era of Targeted Therapy: A Retrospective Study
}

\author{
Jaho Koo ${ }^{1}$, Tae Hoon Roh ${ }^{1, * \mathbb{D}}$, Sang Ryul Lee ${ }^{1}$, Jaesung Heo ${ }^{2}$, Young-Taek $\mathrm{Oh}^{2}$ and Se-Hyuk Kim $^{1}$ \\ 1 Gamma Knife Center, Brain Tumor Center, Department of Neurosurgery, Ajou University Hospital, \\ Ajou University School of Medicine, Suwon 16499, Korea; jaho9188@gmail.com (J.K.); \\ sangryul79@gmail.com (S.R.L.); nsksh@ajou.ac.kr (S.-H.K.) \\ 2 Brain Tumor Center, Department of Radiation Oncology, Ajou University Hospital, Ajou University School of \\ Medicine, Suwon 16499, Korea; mobilehealth@aumc.ac.kr (J.H.); ohyoung@ajou.ac.kr (Y.-T.O.) \\ * Correspondence: throh@ajou.ac.kr
}

check for updates

Citation: Koo, J.; Roh, T.H.; Lee, S.R.; Heo, J.; Oh, Y.-T.; Kim, S.-H. Whole-Brain Radiotherapy vs. Localized Radiotherapy after Resection of Brain Metastases in the Era of Targeted Therapy: A Retrospective Study. Cancers 2021, 13, 4711. https://doi.org/10.3390/ cancers13184711

Academic Editor: Paul Lockman

Received: 13 August 2021

Accepted: 17 September 2021

Published: 20 September 2021

Publisher's Note: MDPI stays neutral with regard to jurisdictional claims in published maps and institutional affiliations.

Copyright: (c) 2021 by the authors. Licensee MDPI, Basel, Switzerland. This article is an open access article distributed under the terms and conditions of the Creative Commons Attribution (CC BY) license (https:// creativecommons.org/licenses/by/ $4.0 /)$.
Simple Summary: The paradigm shift from cytotoxic chemotherapy to molecular targeted therapy dramatically improved the survival and quality of life of cancer patients. In radio-oncological aspects, there also was a paradigm shift from whole-brain radiotherapy to localized radiotherapy including stereotactic radiosurgery. This retrospective study analyzed 124 consecutive patients who had undergone surgical resection of brain metastases. We found targeted therapies to improve overall survival and distant control with decreased incidence of leptomeningeal metastasis. Our data suggest that localized radiotherapy is sufficient after resection of brain metastases when systemic targeted therapy is available.

Abstract: Whether targeted therapy (TT) and radiotherapy impact survival after resection of brain metastases (BM) is unknown. The purpose of this study was to analyze the factors affecting overall survival (OS), local control (LC), distant control (DC), and leptomeningeal metastases (LMM) in patients who had undergone resection of BM. We retrospectively analyzed 124 consecutive patients who had undergone resection of BM between 2004 and 2020. Patient information about age, sex, Karnofsky Performance Scale (KPS), origin of cancer, synchronicity, tumor size, status of primary cancer, use of TT, extent of resection, and postoperative radiotherapy was collected. Radiation therapy was categorized into whole-brain radiotherapy (WBRT), localized radiotherapy (local brain radiotherapy or stereotactic radiosurgery (LBRT/SRS)), and no radiation. We identified factors that affect OS, LC, DC, and LMM. In multivariable analysis, significant factors for OS were higher KPS score $(\geq 90)$ (HR 0.53, $p=0.011)$, use of TT (HR 0.43, $p=0.001)$, controlled primary disease (HR 0.63 , $p=0.047)$, and single BM (HR 0.55, $p=0.016)$. Significant factors for LC were gross total resection (HR 0.29, $p=0.014$ ) and origin of cancer $(p=0.041)$. Both WBRT and LBRT/SRS showed superior LC than no radiation (HR 0.32, $p=0.034$ and HR $0.38, p=0.018$, respectively). Significant factors for DC were use of TT (HR 0.54, $p=0.022$ ) and single BM (HR 0.47, $p=0.004)$. Reduced incidence of LMM was associated with use of TT (HR 0.42, $p=0.038$ ), synchronicity (HR 0.25, $p=0.028$ ), and controlled primary cancer (HR $0.44, p=0.047$ ). TT was associated with prolonged OS, improved DC, and reduced LMM in resected BM patients. WBRT and LBRT/SRS showed similar benefits on LC. Considering the extended survival of cancer patients and the long-term effect of WBRT on cognitive function, LBRT/SRS appears to be a good option after resection of BM.

Keywords: brain metastases; radiosurgery; targeted therapy; survival; surgery 


\section{Introduction}

Brain metastasis (BM) occurs in $20-40 \%$ of cancer patients and results in shorter survival and poor quality of life [1,2]. The incidence of BM is increasing, with prolonged survival owing to the development of cancer therapies such as targeted therapy (TT) [3].

For small BMs without symptoms, radiotherapy or radiosurgery is a mainstay for treatment. Whole-brain radiotherapy (WBRT) was the first standard therapy for BM and showed survival benefits [4]. Stereotactic radiosurgery (SRS) also proved to have survival benefits in patients with 1-10 BMs [5]. WBRT followed SRS to prevent distant metastases, but many studies have questioned the role of additional WBRT after SRS because it shows no clear survival benefit [6]. Moreover, WBRT was related to cognitive impairment and poor quality of life [7].

Surgical resection is a standard treatment for a single BM, especially when it is large in size and causes a mass effect or obstructive hydrocephalus [8-10]. However, patients who had undergone surgical treatment for BM were exposed to a higher risk of leptomeningeal metastases (LMM) compared with patients who had received SRS [11-13]. WBRT can prevent local and distant recurrences, LMM, and death due to neurological causes in such patients $[4,11]$. However, since the death of cancer patients was dependent on systemic progression of disease, WBRT after resection of BM did not show a clear survival benefit [6].

Cognitive decline and neurotoxicity after WBRT have shifted attention to localized radiotherapy, such as SRS, as an alternative treatment [14]. Furthermore, fractionated stereotactic radiation therapy (FSRT) has emerged as a treatment for large BM [15]. Moreover, local brain radiotherapy (LBRT) to the resection cavity showed similar LC compared with WBRT [16-18].

Recently, advances in molecular TT and immune checkpoint inhibitors dramatically improved the survival of some cancer patients. Thus, the quality of life of cancer patients is of more concern than in the past. Many centers are deferring WBRT after resection of BM, while adopting localized radiotherapy such as LBRT, FSRT, or SRS [19]. However, little is known about the differences in long-term outcomes of these modalities. Furthermore, the effects of TT on postoperative recurrences are not well known. In this study, we analyzed and identified the factors affecting overall survival (OS), local control (LC), distal control (DC), and leptomeningeal metastasis (LMM) in patients who had undergone surgical resection of BM.

\section{Materials and Methods}

We retrospectively analyzed consecutive patients who had undergone surgical treatment for metastatic brain tumors in our institute between June 2004 and December 2020. Patient information on age, sex, Karnofsky Performance Scale (KPS) score, day of operation, method of radiation therapy (fraction, dose, time), and status of primary cancer was collected from electronic medical records. Information on extent of resection and number of BMs also was collected. Indications for surgical resection for BM were the presence of related neurological symptoms or mass effects in a surgically accessible location. If there were multiple BMs, only symptomatic lesions were resected. KPS scores were measured based on preoperative conditions. Postoperative treatment modality was determined through a multidisciplinary conference in each case. The presence of recurrence was determined based on RANO-BM criteria [20]. LMM was determined by brain or spine magnetic resonance image (MRI) or cerebrospinal fluid cytology. Brain MRI was performed every 3 months after surgery in patients with residual lesions and every 6 months if the patient had no symptoms or was stable. The OS was defined as the time from surgery to last visit or death. Follow-up duration and recurrence were based on the last MRI performed from the date of surgery. Distant recurrence was defined as a case of a new lesion distant from the resected cavity.

Radiation therapy was divided into three groups of LBRT/SRS, WBRT, and no radiation. The LBRT/SRS group comprised patients who had received radiation other than WBRT. Although fractionation of radiation varied depending on size of the resection cavity, 
a similar biologically equivalent dose (BED) was applied across the LBRT/SRS group. We grouped these localized radiotherapies as a counterpart to WBRT. For LBRT, patients underwent a simulation in the supine position with a mask device using a computed tomography (CT) scanner with $3 \mathrm{~mm}$ slice intervals for three-dimensional RT planning. The initial clinical target volume (CTV) contained an entire resection cavity. The planning target volume (PTV) was defined as the CTV plus an at least $2 \mathrm{~mm}$ margin. This margin was modified around natural barriers such as the skull, ventricles, and falx. Organs at risk (OAR) were defined as the brain stem, optic nerves, and optic chiasm. For SRS, patients were treated with the Leksell GammaKnife ${ }^{\circledR}$ (Model C or Icon ${ }^{\mathrm{TM}}$; Elekta AB, Stockholm, Sweden) either fixed by Leksell Frame for single session or by thermoplastic mask for multiple sessions. The prescription dose was determined by diameter of the resection cavity. Resection cavities with diameters $<1,1-2,2-3$, and $>3 \mathrm{~cm}$ received 20, 18-20, 16-18, and $12-16$ Gy, respectively.

In contrast with cytotoxic chemotherapy, patients treated postoperatively with any drugs that target specific molecular pathways including cancer-driving mutation, growth factors, transcription factors, hormone receptors, or immune checkpoint were grouped as TT in our study.

The survival was calculated using the Kaplan-Meier estimate and compared between groups using a log-rank test. A Cox proportional hazards model was used for univariable and multivariable analyses for OS, LC, DC, and LMM.

All research was performed following institutional guidelines and the Declaration of Helsinki of 1975 in its most recent version. The institutional review board permitted this study. Patient consent was waived due to the retrospective nature of this study.

\section{Results}

\subsection{Patient and Treatment Characteristics}

One hundred fifty-nine patients received surgery for BM between 2004 and 2020. A total of 35 patients were excluded because 19 died within three months, and 16 were lost to follow-up. One hundred twenty-four patients were included in the analysis. A total of $26(21.0 \%)$ patients received LBRT, and $37(29.8 \%)$ received single-session SRS to the resection cavity. Thus, $63(50.8 \%)$ patients were included in the LBRT/SRS group. A total of $24(19.4 \%)$ patients received WBRT, and $37(29.8 \%)$ did not receive adjuvant radiation therapy after surgery for BM. No patient received localized radiotherapy plus WBRT before recurrence. The median number of fractions of LBRT was 10 (range 3-29), and the median radiation dose was $30 \mathrm{~Gy}$. The median imaging follow-up period for patients without local recurrence was 8.2 months (range: $0.4-105.4$ months). The median treatment time from surgery to adjuvant radiation therapy was 15 days (range: 0-63 days) for LBRT/SRS and 19 days (range: $0-28$ days) for WBRT.

Patient demographics are indicated in Table 1. The median age was 57.7 years (range: 28-78 years), and the median KPS score was 90 (range: 30-100). Primary disease was located in lung $(50,40.3 \%)$, breast $(34,27.4 \%)$, gastrointestinal tract $(12,9.7 \%)$, ovarian, uterus or cervix $(10,8.1 \%)$, genitourinary tract $(6,4.8 \%)$, head and neck $(5,4.0 \%)$, hepatobiliary $(4,3.2 \%)$, and melanoma $(3,2.4 \%)$. Of the patients, 91 had metachronous BM (73.4\%) and 33 had synchronous BM (26.6\%). The mean preoperative tumor diameter was $3.9 \pm 1.27 \mathrm{~cm}$, and $97(78.2 \%)$ patients had BM size greater than $3 \mathrm{~cm}$. A total of $50(40.3 \%)$ patients were treated using TT. Targeted agents used were 15 for EGFR, 11 for HER2, 8 for ER/PR, 6 for VEGF, 4 for PD-1, 2 for ALK, 2 for mTOR, and 2 for PARP (Table 1). 
Table 1. Patient characteristics.

\begin{tabular}{|c|c|}
\hline Characteristic & Count (\%) \\
\hline Age & $59(28-78) *$ \\
\hline \multicolumn{2}{|l|}{ Sex } \\
\hline Men & $59(47.6)$ \\
\hline Women & $65(52.4)$ \\
\hline \multicolumn{2}{|l|}{ Postoperative radiotherapy } \\
\hline LBRT/SRS & $63(50.8)$ \\
\hline WBRT & $24(19.4)$ \\
\hline No radiation & $37(29.8)$ \\
\hline Karnofsky Performance Scale & $90(30-100) *$ \\
\hline$\geq 90$ & $68(54.8)$ \\
\hline$<90$ & $56(45.2)$ \\
\hline \multicolumn{2}{|l|}{ Primary site } \\
\hline Non-small cell lung cancer & $41(33.1)$ \\
\hline Small cell lung cancer & $9(7.3)$ \\
\hline Breast & $34(27.4)$ \\
\hline Gastrointestinal & $12(9.7)$ \\
\hline Gynecologic & $10(8.1)$ \\
\hline Genitourinary & $6(4.8)$ \\
\hline Head and Neck & $5(4.0)$ \\
\hline Hepatobiliary & $4(3.2)$ \\
\hline Melanoma & $3(2.4)$ \\
\hline \multicolumn{2}{|l|}{ Synchronicity } \\
\hline Metachronous & $91(73.4)$ \\
\hline Synchronous & $33(26.6)$ \\
\hline Tumor size & $3.75 \mathrm{~cm}(1.3-7.6 \mathrm{~cm})$ * \\
\hline$\geq 3 \mathrm{~cm}$ & $97(78.2)$ \\
\hline$<3 \mathrm{~cm}$ & $27(21.8)$ \\
\hline \multicolumn{2}{|l|}{ Targeted therapy } \\
\hline Targeted therapy (+) & $50(40.3)$ \\
\hline EGFR & 15 \\
\hline HER2 & 11 \\
\hline $\mathrm{ER} / \mathrm{PR}$ & 8 \\
\hline VEGF & 6 \\
\hline PD-1 & 4 \\
\hline ALK & 2 \\
\hline mTOR & 2 \\
\hline PARP & 2 \\
\hline Targeted therapy $(-)$ & $74(59.7)$ \\
\hline \multicolumn{2}{|l|}{ Systemic control } \\
\hline Controlled & $66(53.2)$ \\
\hline Uncontrolled & $58(46.8)$ \\
\hline \multicolumn{2}{|l|}{ Extent of resection } \\
\hline Gross total resection & 109 (87.9) \\
\hline Subtotal resection & $15(12.1)$ \\
\hline \multicolumn{2}{|l|}{ Multiplicity } \\
\hline Single & $64(51.6)$ \\
\hline Multiple & $60(48.4)$ \\
\hline
\end{tabular}

LBRT, local brain radiotherapy; SRS, stereotactic radiosurgery; WBRT, whole-brain radiotherapy; EGFR, epidermal growth factor receptor; HER2, human epidermal growth factor receptor 2; ER, estrogen receptor; PR, progesterone receptor; VEGF, vascular endothelial growth factor; PD-1, programmed cell death protein 1; ALK, Anaplastic lymphoma kinase; mTOR, mammalian target of rapamycin; PARP, Poly (ADP-ribose) polymerase; * Median (range).

\subsection{Overall Survival (OS)}

As of May 2021, 84 (67.7\%) of these patients were dead. The median follow-up duration was 45.8 months (95\% CI: 35.6-56.0) by reverse Kaplan-Meier estimate. The median OS of entire cohort was 21.1 months (95\% CI: 15.8-26.4). The Kaplan-Meier estimate for survival probability was $69.4 \%$ at 12 months and $49.2 \%$ at 24 months. 
In univariable analysis, higher ( $\geq 90)$ KPS score (HR 0.53, 95\% CI: (0.27-1.03), $p=0.062$ ), TT (HR 0.43, 95\% CI: (0.25-0.75), $p=0.003)$, controlled systemic disease (HR 0.58, 95\% CI: $(0.34-0.98), p=0.042)$, and single brain metastasis (HR 0.61, 95\% CI: $(0.36-1.04), p=0.07)$ were associated with longer OS.

Kaplan-Meier curves of significant prognostic factors for OS are shown in Figure 1. Median OS was 31.2 months (95\% CI: 21.2-41.2 months) in the KPS score $\geq 90$ group but 14.7 months (95\% CI: 11.9-17.5 months) in the KPS < 90 group. Median OS was 28.9 months in the TT (+) group (95\% CI: 18.2-39.6 months) and 14.7 months (95\% CI: 9.6-19.8 months) in the TT (-) group. Median OS was 33.7 months in the single BM group (95\% CI: 22.1-45.3 months) and 14.9 months (95\% CI: 10.2-19.5 months) in the multiple BM group. Median OS was 24.9 months in the systemic controlled group (95\% CI: 12.8-36.9 months) and 15.6 months (95\% CI: $12.4-18.8)$ in the systemic uncontrolled group $(p=0.087)$. There was no significant difference in OS by type or status of postoperative adjuvant radiation therapy $(p=0.923)$. With regard to primary site, the longest OS was observed for gynecologic cancer (46.2 months, 95\% CI: 11.7-80.7), followed by breast cancer (24.6 months, 95\% CI: 14.6-34.6), gastrointestinal (21.8 months, 95\% CI: 0-51.2), lung (21.7 months, 95\% CI: 16.0-27.5), head and neck (10.4 months), hepatobiliary (8.4 months, 95\% CI: 0.9-15.8), and genitourinary (6.6 months, 95\% CI: 4.0-9.2) ( $p=0.289)$.

A

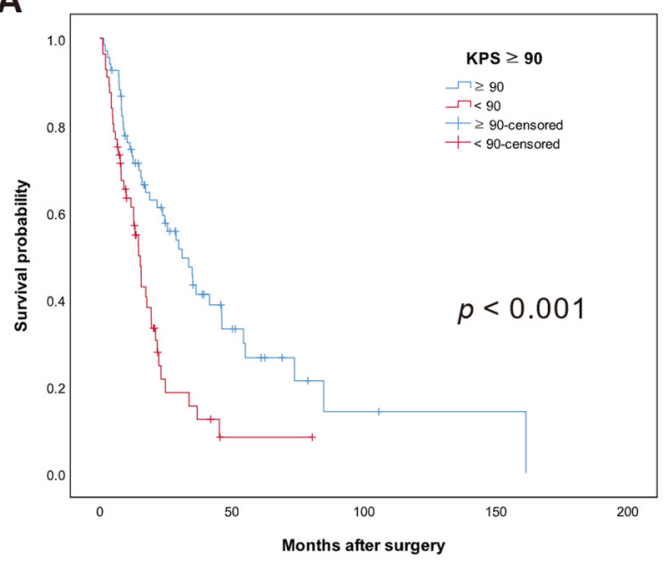

C

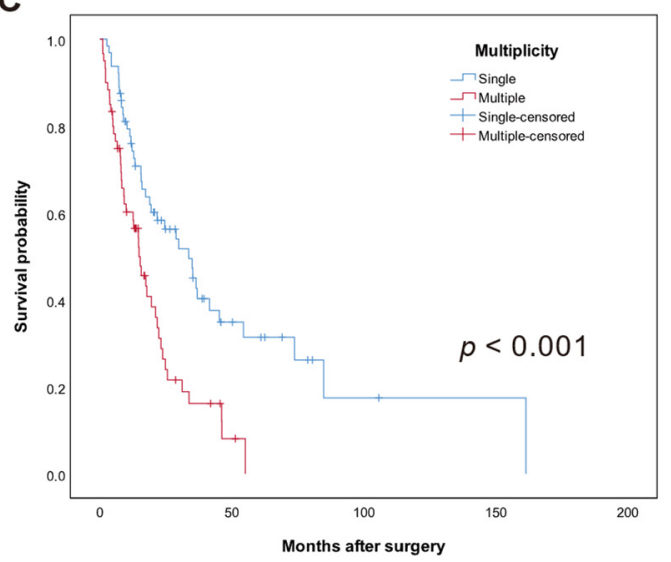

B

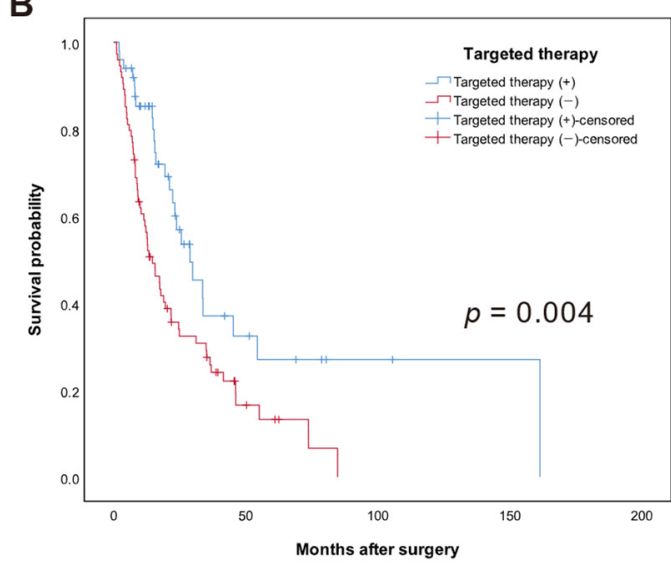

D

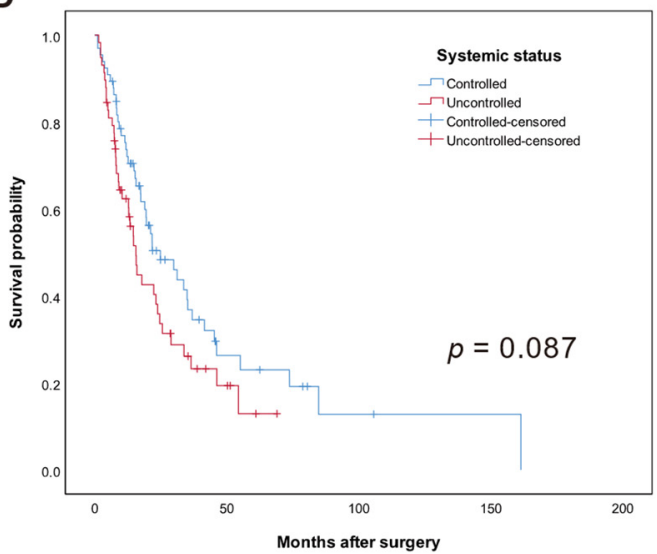

Figure 1. Kaplan-Meier curves of overall survival (OS) in months. The median OS in each group was as follows: (A) KPS score, median survival was 31.2 vs. 14.7 , (KPS $\geq 90$ vs. KPS $<90, p<0.001$ ), (B) use of targeted therapy, median OS was 28.9 vs. 13.4 ( $p=0.004)$, (C) multiplicity of brain metastases, median OS was 33.7 vs. $14.9(p<0.001)$, (D) condition of systemic control, median OS was 24.9 vs. $15.6(p=0.006)$.

In multivariable analysis, higher $(\geq 90)$ KPS score (HR 0.53, 95\% CI: 0.32-0.87, $p=0.011$ ), TT (HR 0.43, 95\% CI: 0.26-0.70, $p=0.001$ ), controlled systemic disease (HR 0.63, 95\% CI: 
$0.40-1.00, p=0.047$ ), and single brain metastasis (HR 0.55, 95\% CI: $0.34-0.90, p=0.016$ ) were associated with longer OS (Table 2).

Table 2. Univariable and multivariable Cox regression for overall survival.

\begin{tabular}{ccccc}
\hline $\begin{array}{c}\text { Overall Survival } \\
\text { Parameters }\end{array}$ & HR (95\% CI) & $p$ & HR (95\% CI) & $p$ \\
\hline Age (per 1 increase) & $1.00(0.97-1.02)$ & 0.795 & \\
Sex (Women: Men) & $0.73(0.32-1.68)$ & 0.464 & \\
Radiation method & & & \\
No radiation & 1 & & \\
WBRT & $1.15(0.56-2.36)$ & 0.701 & & \\
LBRT/SRS & $1.07(0.48-2.37)$ & 0.864 & & \\
KPS $\geq 90$ & $0.53(0.27-1.03)$ & 0.062 & $0.53(0.32-0.87)$ & \\
Primary site & - & 0.701 & \\
Synchronicity & $0.85(0.46-1.60)$ & 0.621 & & \\
Size ( $\geq 3$ cm: $<3$ cm) & $1.11(0.62-1.99)$ & 0.737 & & \\
Targeted therapy & $0.43(0.25-0.75)$ & 0.003 & $0.43(0.26-0.70)$ & 0.001 \\
Systemic control & $0.58(0.34-0.98)$ & 0.042 & $0.63(0.40-1.00)$ & 0.047 \\
Gross total resection & $1.00(0.48-2.07)$ & 0.996 & & \\
Single metastasis & $0.61(0.36-1.04)$ & 0.070 & $0.55(0.34-0.90)$ & 0.016 \\
\hline LBRT, local brain radiotherapy; SRS, stereotactic radiosurgery; WBRT, whole-brain radiotherapy; KPS, Karnofsky \\
performance scale.
\end{tabular}

\subsection{Local Control (LC)}

During the analysis period, 37 (29.8.\%) patients experienced postoperative local recurrence at the resection cavity. LC probability was $75.0 \%$ at 12 months and $71.0 \%$ at 24 months in the entire cohort. Gross total resection was associated with higher LC in univariable (HR 0.29, 95\% CI: $0.11-0.83, p=0.021$ ) and multivariable analyses (HR 0.29 , $95 \%$ CI: $0.11-0.78, p=0.014)$ (Table 3). Origin of cancer $(p=0.041)$ was associated with LC in multivariable analysis. Both WBRT and LBRT/SRS showed superior LC than no radiation (HR 0.32, 95\% CI 0.11-0.92, $p=0.034$ and HR 0.38, 95\% CI 0.17-0.85, $p=0.018$, respectively). There was no significant difference in LC between WBRT and LBRT/SRS ( $p=0.768$ ). The 12 -month LC was $56.8 \%$ in the no radiation group, $81.9 \%$ in the LBRT/SRS group, and $83.3 \%$ in the WBRT group. Kaplan-Meier curves of significant factors for LC are shown in Figure 2.

Table 3. Univariable and multivariable Cox regression for local control.

\begin{tabular}{ccccc}
\hline $\begin{array}{c}\text { Local Control } \\
\text { Parameters }\end{array}$ & $\begin{array}{c}\text { Univariable } \\
\text { HR (95\% CI) }\end{array}$ & $p$ & Multivariable \\
HR (95\% CI) & $p$ \\
\hline Age (per 1 increase) & $0.99(0.95-1.03)$ & 0.469 & & \\
Sex (Women: Men) & $0.92(0.28-3.00)$ & 0.883 & & \\
Radiation method & & & & \\
No radiation & 1 & & $0.32(0.11-0.92)$ & 0.034 \\
WBRT & $0.21(0.06-0.68)$ & 0.009 & & 0.018 \\
LBRT/SRS & $0.37(0.15-0.88)$ & 0.025 & & \\
KPS $\geq 90$ & $0.59(0.22-1.63)$ & 0.31 & & \\
Primary site & & & & \\
Non-small cell lung cancer & 1 & & & \\
Small cell lung cancer & $2.15(0.56-8.28)$ & 0.266 & $3.46(1.02-11.72)$ & 0.047 \\
Breast & $0.85(0.20-3.68)$ & 0.823 & $1.01(0.39-2.64)$ & 0.983 \\
Gastrointestinal & $3.30(1.14-9.59)$ & 0.028 & $3.83(1.39-10.56)$ & 0.009 \\
Gynecologic & $0.40(0.04-4.04)$ & 0.433 & $0.40(0.05-3.14)$ & 0.38 \\
Genitourinary & $0.45(0.07-2.90)$ & 0.398 & $1.12(0.22-5.68)$ & 0.892 \\
Head and neck & $0.33(0.04-2.55)$ & 0.287 & $0.34(0.06-1.96)$ & 0.227 \\
\hline
\end{tabular}


Table 3. Cont.

\begin{tabular}{ccccc}
\hline $\begin{array}{c}\text { Local Control } \\
\text { Parameters }\end{array}$ & $\begin{array}{c}\text { Univariable } \\
\text { HR (95\% CI) }\end{array}$ & $\boldsymbol{p}$ & HR (95\% CI) & $\boldsymbol{p}$ \\
\hline Hepatobiliary & - & 0.981 & - & 0.981 \\
Melanoma & $3.01(0.52-17.43)$ & 0.219 & $3.88(0.78-19.37)$ & 0.098 \\
Synchronicity & $0.47(0.17-1.26)$ & 0.133 & $0.44(0.18-1.07)$ & 0.071 \\
Size $(\geq 3 \mathrm{~cm}:<3 \mathrm{~cm})$ & $0.76(0.32-1.81)$ & 0.539 & & \\
Targeted therapy & $0.64(0.26-1.58)$ & 0.335 & & \\
Systemic control & $0.96(0.44-2.09)$ & 0.91 & & 0.014 \\
Gross total resection & $0.30(0.11-0.83)$ & 0.021 & $0.29(0.11-0.78)$ & \\
Single metastasis & $0.95(0.40-2.26)$ & 0.905 & & \\
\hline
\end{tabular}

LBRT, local brain radiotherapy; SRS, stereotactic radiosurgery; WBRT, whole-brain radiotherapy; KPS, Karnofsky performance scale.
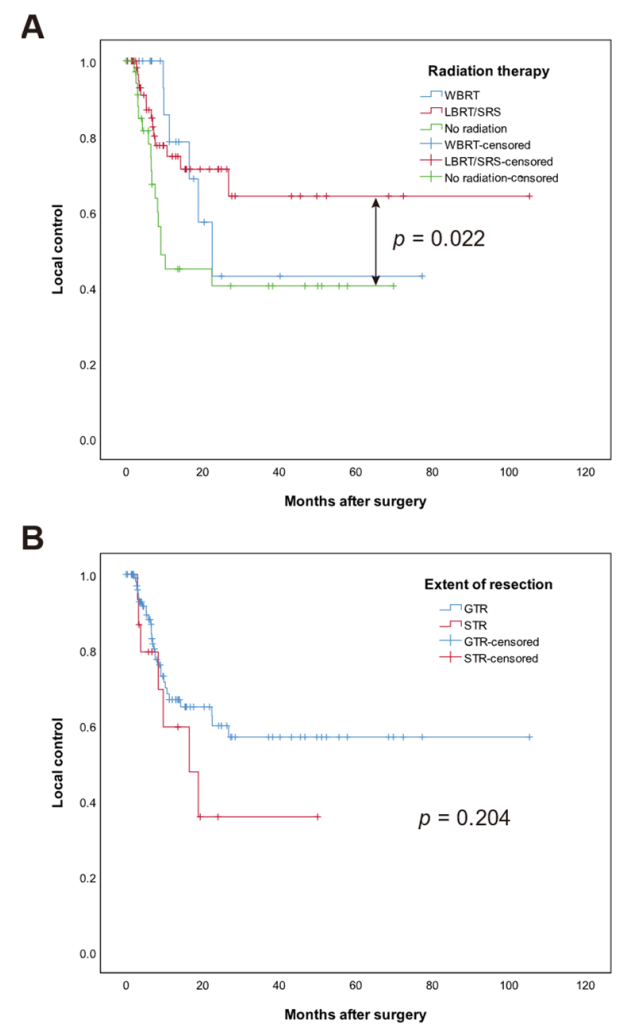

C

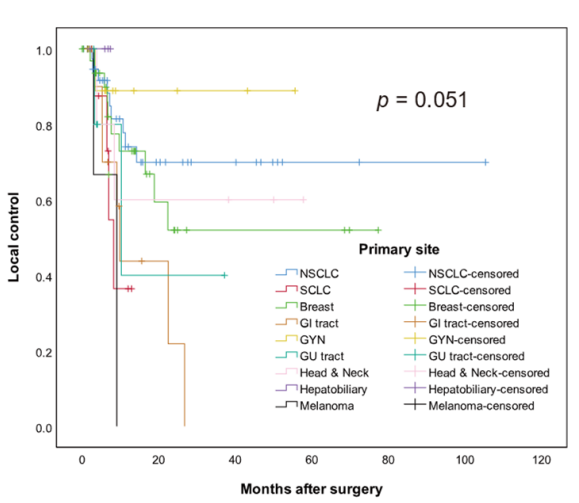

Figure 2. Kaplan-Meier curves of local control (LC) in months among 124 patients. The median LC values in each group were as follows: (A) radiation therapy, mean local recurrence-free survival time was 71.6 vs. 40.4 vs. 33.7, (LBRT/SRS vs. WBRT vs. No radiation, respectively $p=0.022$ ) (B) extent of resection, mean local recurrence-free survival time was 64.4 vs. 24.6 (GTR vs. STR), respectively $(p=0.204),(C)$ primary site of brain metastases $(\mathrm{BM})(p=0.051)$. 


\subsection{Distant Control (DC)}

A total of 61 patients (49.2\%) had developed new BM outside of the resected region during the follow-up period. The 12 months distant brain control was $66.9 \% ; 24$ months was $54.8 \%$. Median DC was 16.5 months (95\% CI: 11.9-21.2) for the entire cohort. In univariate analysis, using TT (HR $0.45,95 \%$ CI: $0.23-0.88, p=0.02$ ) and single brain metastasis (HR 0.53 , $95 \%$ CI: $0.28-0.98, p=0.044)$ were associated with higher DC (Table 4). In multivariate analysis, using TT (HR 0.54, 95\% CI: 0.32-0.91, $p=0.022$ ) and single brain metastasis (HR 0.47, 95\% CI: $0.29-0.79, p=0.004$ ) were associated with higher DC. Kaplan-Meier curves of significant factors for DC are shown in Figure 3.

Table 4. Univariable and multivariable Cox regression for distant control.

\begin{tabular}{ccccc}
\hline $\begin{array}{c}\text { Distant Control } \\
\text { Parameters }\end{array}$ & $\begin{array}{c}\text { Univariable } \\
\text { HR (95\% CI) }\end{array}$ & $p$ & $\begin{array}{c}\text { Multivariable } \\
\text { HR (95\% CI) }\end{array}$ & $p$ \\
\hline Age (per 1 increase) & $0.98(0.95-1.01)$ & 0.184 & \\
Sex (Women: Men) & $0.68(0.27-1.71)$ & 0.411 & \\
Radiation method & & & \\
No radiation & 1 & & \\
WBRT & $0.86(0.34-2.18)$ & 0.756 & \\
LBRT/SRS & $1.41(0.69-2.89)$ & 0.349 & \\
KPS $\geq 90$ & $0.65(0.30-1.38)$ & 0.261 & \\
Primary site & - & 0.865 & & \\
Synchronicity & $0.80(0.38-1.66)$ & 0.542 & & \\
Size ( $\geq 3$ cm; $<3$ cm) & $1.35(0.71-2.58)$ & 0.355 & & \\
Targeted therapy & $0.45(0.23-0.88)$ & 0.020 & $0.54(0.32-0.91)$ & 0.022 \\
Systemic control & $0.70(0.37-1.32)$ & 0.265 & & \\
Gross total resection & $0.71(0.34-1.52)$ & 0.384 & & \\
Single metastasis & $0.53(0.28-0.98)$ & 0.044 & $0.47(0.29-0.79)$ & 0.004 \\
\hline
\end{tabular}

LBRT, local brain radiotherapy; SRS, stereotactic radiosurgery; WBRT, whole-brain radiotherapy; KPS, Karnofsky performance scale.

A

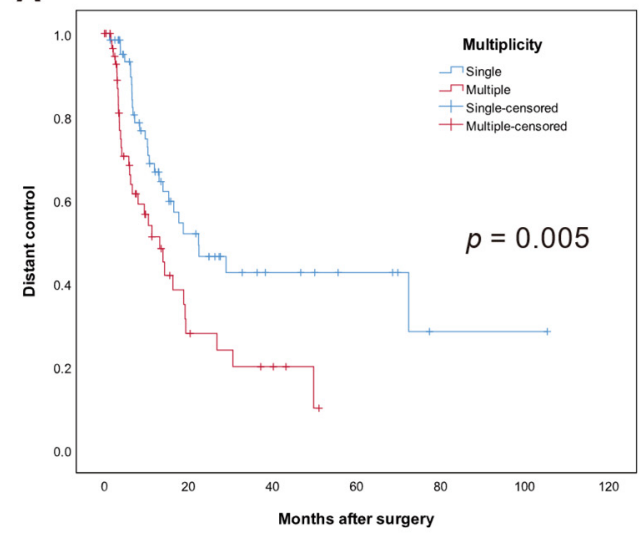

B

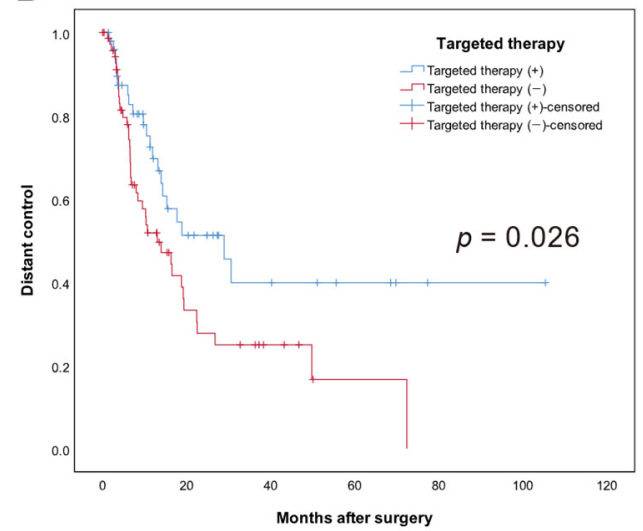

Figure 3. Kaplan-Meier curves of distant control (DC) in months among 124 patients. (A) Median distant-free survival time was 22.4 vs. 13.2 for single vs. multiple brain metastases, respectively $(p=0.005)$, (B) Median distant-free survival time was 29.0 vs. 13.0 with use of targeted therapy vs. no use of targeted therapy $(p=0.026)$.

\subsection{Leptomeningeal Metastases (LMM)}

In total, 27 patients (21.8\%) developed radiologically or cytologically confirmed LMM at a median of 72.4 months (95\% CI: 2.2-142.6 months). Melanoma and breast cancer had the highest incidence of LMM $(66.7 \%$ and $38.2 \%$, respectively), but the difference was not significant $(p=0.293)$. There was no significant factor identified in the univariable analysis. However, multivariable analysis revealed that synchronous BM (HR 0.25, 95\% CI: $0.08-0.86, p=0.028$ ), TT (HR 0.42, 95\% CI: 0.18-0.95, $p=0.038$ ), and controlled systemic 
disease (HR 0.44, 95\% CI: 0.20-0.99, $p=0.047$ ) were associated with lower incidence of LMM (Table 5).

Table 5. Univariable and multivariable Cox regression for leptomeningeal metastases.

\begin{tabular}{ccccc}
\hline $\begin{array}{c}\text { Leptomeningeal Metastases } \\
\text { Parameters }\end{array}$ & $\begin{array}{c}\text { Univariable } \\
\text { HR (95\% CI) }\end{array}$ & $p$ & Mr (95\% CI) & $p$ \\
\hline Age (per 1 increase) & $1.03(0.96-1.09)$ & 0.430 & & \\
Sex (Women: Men) & $3.98(0.43-37.31)$ & 0.226 & & \\
Radiation method & & & & \\
No radiation & 1 & & & \\
WBRT & $1.72(0.36-8.13)$ & 0.493 & & \\
LBRT/SRS & $1.31(0.41-4.15)$ & 0.646 & & \\
KPS $\geq 90$ & $1.23(0.36-4.18)$ & 0.741 & & \\
Primary site & - & 0.293 & & \\
Synchronicity & $0.29(0.07-1.26)$ & 0.099 & $0.25(0.08-0.86)$ & \\
Size ( $\geq 3$ cm; $<3$ cm) & $0.65(0.21-2.02)$ & 0.458 & & \\
Targeted therapy & $0.46(0.16-1.33)$ & 0.153 & $0.42(0.18-0.95)$ & 0.038 \\
Systemic control & $0.55(0.21-1.44)$ & 0.223 & $0.44(0.20-0.99)$ & 0.047 \\
Gross total resection & $0.79(0.24-2.66)$ & 0.707 & & \\
Single metastasis & $0.47(0.19-1.17)$ & 0.105 & $0.47(0.22-1.02)$ & 0.055 \\
\hline
\end{tabular}

LBRT, local brain radiotherapy; SRS, stereotactic radiosurgery; WBRT, whole-brain radiotherapy; KPS, Karnofsky performance scale.

\section{Discussion}

There have been many studies on postoperative survival and recurrence of BM, but not many have included TT as a prognostic factor. Our study was the first to analyze survival and recurrence after resection of BM with both TT and WBRT. The results suggest that the use of TT is associated with longer survival, better DC, and a lower risk of LMM.

In the updated Graded Prognostic Assessment (GPA), which is the most reliable prognostic index for brain metastases, molecular markers with available TT were significant prognostic factors in breast, non-small cell lung cancer (NSCLC), and melanoma [21-23]. Our data suggest that TT remains prognostic in the subset of patients who underwent surgical treatment for BM.

It is well known that a higher KPS score is related to a better prognosis of BM patients [24,25]. KPS score is the most important prognostic factor used to calculate all known prognostic scoring systems for BM, including GPA, recursive partitioning analysis (RPA), the score index for radiosurgery (SIR), and the basic score for brain metastases (BSBM) [21,26-29]. In this study, it was confirmed that the OS was a significant factor in the patient group with KPS score $\geq 90$ ( $p=0.011$ in multivariate). Additionally, prognostic factors for OS were status of systemic disease and the number of metastatic brain tumors, as previously reported in other studies [23,30]. Single metastasis was significantly associated with better OS $(p=0.016)$.

Prognostic factors affecting postoperative local recurrence in patients with metastatic brain tumors are known to be extent of resection and postoperative WBRT or SRS [30,31]. In our study, both WBRT $(p=0.034)$ and LBRT/SRS $(p=0.018)$ were associated with better LC than was no radiation. Gross total resection also showed better LC $(p=0.014)$. The effect of TT on LC was not significant $(p=0.335)$, possibly due to a small number $(29.8 \%)$ of patients who had local recurrence during the follow-up period.

Previous studies have shown that single BM and WBRT were favoring factors for DC after surgery in patients with BM [31]. In our study, TT ( $p=0.022)$ and single metastatic cancer $(p=0.004)$ were significant for high DC. WBRT did not seem to compensate for the prognostic disadvantage of multiple metastases in our study. No other studies have revealed the effect of TT on DC after surgery of metastatic brain tumors. Given that TT is a treatment that inhibits the proliferation of tumor cells by interfering with specific target molecules, it is plausible that TT can improve DC. 
In our study, LC and DC were $75.0 \%$ and $66.9 \%$ at 12 months, respectively. In particular, 26.3 months after the surgery, there was no additional local recurrence. These results indicate that BM itself can be well controlled with appropriate treatment, and that it is due to systemic disease progression that affects OS. This is consistent with the findings of this study, where the presence of systemic control $(p=0.027)$ is significant to OS.

Patients with BM who need surgery typically have a poor prognosis [32]. However, since the introduction of TT, more patients survive for a long time even if they have BM, and the follow-up period has been prolonged [33]. TT also has been shown to affect BM [34-36]. Newer-generation tyrosine kinase inhibitors are thought to be more effective against BMs because they are more permeable to the blood-brain barrier [37]. Based on this assumption, clinical trials of BM patients with TT are ongoing. The OUTRUN trial is a randomized phase II trial that compares TT only and TT plus SRS (ClinicalTrials.gov identifier: NCT03497767). The ORBITAL trial includes BM patients even if they have LMM (ClinicalTrials.gov identifier: NCT04233021).

The OS of patients with BM who have undergone surgery was not related to the type of radiation treatments, including SRS and WBRT [38]. Our study showed that LBRT/SRS has advantages in terms of LC over no radiation. Previously, when the survival was short after the onset of BM in a cancer patient, decline in cognitive function caused by WBRT was rarely noticed. However, as cancer treatment developed and prolonged survival, local treatments such as SRS rather than WBRT were used to improve the quality of life [39], which had no adverse effect on cognition but an equivalent LC effect as WBRT [40].

Postoperative WBRT reduces the possibility of LMM [41]. However, no survival benefit was proven in previous studies with postoperative WBRT [6]. Our study also did not show a significant difference in the incidence of LMM between LBRT/SRS and WBRT groups $(p=0.493)$. Interestingly, use of TT was related to a lower incidence of LMM $(p=0.038)$ in our study. To the best of our knowledge, this finding is original. This result suggests that TT can suppress the development of LMM. The other possibility is that the intrinsic nature of cancer differs among subtypes, with some having greater possibility to seed LMM [42]. Another explanation for this finding would be "just chance" due to small patient numbers, which is the one of limitations of this study. Nonetheless, TT had a survival benefit for patients with LMM with EGFR-mutated NSCLC [43,44]. For wild-type EGFR NSCLC, WBRT performed even after confirmation of LMM survival benefit in a retrospective study [41]. Taken together, these findings suggest that WBRT can be deferred until LMM occurs.

SRS in the resection cavity can be administered either as a single session or in fractions. However, it has not been revealed which of the two methods is more effective in LC for BM. For large unresected BM, fractionated SRS is known to have better LC and lower radiation necrosis than single session SRS [45]. Similar to in cavity radiosurgery, fractionation enables larger target volume with the same BED enabling a $2 \mathrm{~mm}$ margin radiation, which is known to improve LC [46,47]. Thus, fractionated SRS is expected to play a major role in postoperative SRS.

This study is limited in that it presented an analysis of the results in a relatively small number of patients with limited distribution as a retrospective study in a single institution. Selection bias cannot be ruled out. We do not know which specific TT had the greatest effect on survival. Given that 34 patients received TT for EGFR, HER2, or ER/PR and 16 patients received other TT, the better OS reported for TT is possibly due to effects seen in the EGFR/HER2/ER/PR group. However, because the number of patients using each TT was small, the differences in effectiveness between the TTs were not significant. Further prospective studies in a large-scale cohort are mandatory to reveal the efficacy of TT and localized radiotherapy on the survival and quality of life in patients with BM.

\section{Conclusions}

This analysis suggests that TT improved the survival of patients who had undergone surgical resection of BM. We reaffirmed that well-known prognostic factors such as KPS, 
controlled primary cancer, and number of BMs are significant for survival in this cohort. We did not observe any differences in OS, DC, or LMM for WBRT versus LBRT/SRS. However, this result should be interpreted with caution due to the limited number of cases. Given that longer survival is achieved with systemic therapy rather than radiation, more lesiontargeted radiotherapies that avoid neurotoxicity are reasonable choices. Targeting both molecular and stereotactic targets will be key to maximizing the survival of BM patients while maintaining their quality of life.

Author Contributions: Conceptualization, J.K. and T.H.R.; data curation, S.R.L.; formal analysis, J.K. and T.H.R.; funding acquisition, T.H.R.; supervision, T.H.R. and S.-H.K.; writing-original draft, J.K. and T.H.R.; writing-review and editing, T.H.R., J.H., Y.-T.O. and S.-H.K. All authors have read and agreed to the published version of the manuscript.

Funding: This work was supported by a National Research Foundation of Korea (NRF) grant (NRF-2019R1G1A1011569) and by the Bio \& Medical Technology Development Program of the NRF (NRF-2020M3A9E8024890) funded by the Korean government (MSIT) (T.H.R.).

Institutional Review Board Statement: The study was conducted according to the guidelines of the Declaration of Helsinki, and the study was approved by the Institutional Review Board of Ajou University Hospital (AJIRB-MED-MDB-21-381).

Informed Consent Statement: Patient consent was waived due to the retrospective nature of this study.

Data Availability Statement: No new data were created or analyzed in this study. Data sharing is not applicable to this article.

Conflicts of Interest: The authors declare no conflict of interest.

\section{References}

1. Zhang, X.; Zhang, W.; Cao, W.-D.; Cheng, G.; Liu, B.; Cheng, J. A Review of Current Management of Brain Metastases. Ann. Surg. Oncol. 2012, 19, 1043-1050. [CrossRef] [PubMed]

2. Paek, S.H.; Audu, P.B.; Sperling, M.R.; Cho, J.; Andrews, D.W. Reevaluation of Surgery for the Treatment of Brain Metastases: Review of 208 Patients with Single or Multiple Brain Metastases Treated at One Institution with Modern Neurosurgical Techniques. Neurosurgery 2005, 56, 1021-1034. [CrossRef] [PubMed]

3. Chamberlain, M.C.; Baik, C.S.; Gadi, V.K.; Bhatia, S.; Chow, L.Q.M. Systemic Therapy of Brain Metastases: Non-Small Cell Lung Cancer, Breast Cancer, and Melanoma. Neuro-Oncol. 2017, 19, i1-i24. [CrossRef] [PubMed]

4. $\quad$ Patchell, R.A.; Tibbs, P.A.; Regine, W.F.; Dempsey, R.J.; Mohiuddin, M.; Kryscio, R.J.; Markesbery, W.R.; Foon, K.A.; Young, B. Postoperative Radiotherapy in the Treatment of Single Metastases to the Brain: A Randomized Trial. JAMA 1998, 280, 1485-1489. [CrossRef]

5. Yamamoto, M.; Serizawa, T.; Shuto, T.; Akabane, A.; Higuchi, Y.; Kawagishi, J.; Yamanaka, K.; Sato, Y.; Jokura, H.; Yomo, S.; et al. Stereotactic Radiosurgery for Patients with Multiple Brain Metastases (JLGK0901): A Multi-Institutional Prospective Observational Study. Lancet Oncol. 2014, 15, 387-395. [CrossRef]

6. Kocher, M.; Soffietti, R.; Abacioglu, U.; Villà, S.; Fauchon, F.; Baumert, B.G.; Fariselli, L.; Tzuk-Shina, T.; Kortmann, R.-D.; Carrie, C.; et al. Adjuvant Whole-Brain Radiotherapy Versus Observation After Radiosurgery or Surgical Resection of One to Three Cerebral Metastases: Results of the EORTC 22952-26001 Study. J. Clin. Oncol. 2011, 29, 134-141. [CrossRef]

7. Li, J.; Bentzen, S.M.; Li, J.; Renschler, M.; Mehta, M.P. Relationship Between Neurocognitive Function and Quality of Life After Whole-Brain Radiotherapy in Patients With Brain Metastasis. Int. J. Radiat. Oncol. 2008, 71, 64-70. [CrossRef]

8. Bhangoo, S.S.; Linskey, M.E.; Kalkanis, S.N. Evidence-Based Guidelines for the Management of Brain Metastases. Neurosurg. Clin. N. Am. 2011, 22, 97-104. [CrossRef]

9. Al-Shamy, G.; Sawaya, R. Management of Brain Metastases: The Indispensable Role of Surgery. J. Neurooncol. 2009, 92, 275. [CrossRef]

10. Patchell, R.A.; Tibbs, P.A.; Walsh, J.W.; Dempsey, R.J.; Maruyama, Y.; Kryscio, R.J.; Markesbery, W.R.; Macdonald, J.S.; Young, B. A Randomized Trial of Surgery in the Treatment of Single Metastases to the Brain. N. Engl. J. Med. 1990, 322, 494-500. [CrossRef]

11. Jung, J.; Kim, S.; Joo, J.; Shin, K.H.; Gwak, H.-S.; Lee, S.H. Incidence and Risk Factors for Leptomeningeal Carcinomatosis in Breast Cancer Patients with Parenchymal Brain Metastases. J. Korean Neurosurg. Soc. 2012, 52, 193-199. [CrossRef]

12. Patel, A.J.; Suki, D.; Hatiboglu, M.A.; Abouassi, H.; Shi, W.; Wildrick, D.M.; Lang, F.F.; Sawaya, R. Factors Influencing the Risk of Local Recurrence after Resection of a Single Brain Metastasis: Clinical Article. J. Neurosurg. 2010, 113, 181-189. [CrossRef]

13. Johnson, M.D.; Avkshtol, V.; Baschnagel, A.M.; Meyer, K.; Ye, H.; Grills, I.S.; Chen, P.Y.; Maitz, A.; Olson, R.E.; Pieper, D.R.; et al. Surgical Resection of Brain Metastases and the Risk of Leptomeningeal Recurrence in Patients Treated With Stereotactic Radiosurgery. Int. J. Radiat. Oncol. 2016, 94, 537-543. [CrossRef] [PubMed] 
14. Chang, E.L.; Wefel, J.S.; Hess, K.R.; Allen, P.K.; Lang, F.F.; Kornguth, D.G.; Arbuckle, R.B.; Swint, J.M.; Shiu, A.S.; Maor, M.H.; et al. Neurocognition in Patients with Brain Metastases Treated with Radiosurgery or Radiosurgery plus Whole-Brain Irradiation: A Randomised Controlled Trial. Lancet Oncol. 2009, 10, 1037-1044. [CrossRef]

15. Kim, Y.-J.; Cho, K.H.; Kim, J.-Y.; Lim, Y.K.; Min, H.S.; Lee, S.H.; Kim, H.J.; Gwak, H.S.; Yoo, H.; Lee, S.H. Single-Dose Versus Fractionated Stereotactic Radiotherapy for Brain Metastases. Int. J. Radiat. Oncol. 2011, 81, 483-489. [CrossRef] [PubMed]

16. Suh, J.H.; Kotecha, R.; Chao, S.T.; Ahluwalia, M.S.; Sahgal, A.; Chang, E.L. Current Approaches to the Management of Brain Metastases. Nat. Rev. Clin. Oncol. 2020, 17, 279-299. [CrossRef]

17. Minniti, G.; Niyazi, M.; Andratschke, N.; Guckenberger, M.; Palmer, J.D.; Shih, H.A.; Lo, S.S.; Soltys, S.; Russo, I.; Brown, P.D.; et al. Current Status and Recent Advances in Resection Cavity Irradiation of Brain Metastases. Radiat. Oncol. 2021, 16, 73. [CrossRef]

18. Barbour, A.B.; Jacobs, C.D.; Williamson, H.; Floyd, S.R.; Suneja, G.; Torok, J.A.; Kirkpatrick, J.P. Radiation Therapy Practice Patterns for Brain Metastases in the United States in the Stereotactic Radiosurgery Era. Adv. Radiat. Oncol. 2020, 5, 43-52. [CrossRef]

19. Kim, S.K.; Park, J.E.; Kim, K.H.; Cho, J.M.; Moon, J.; Yoon, W.-S.; Kim, S.H.; Kim, Y.I.; Kim, Y.Z.; Kim, H.S.; et al. A National Consensus Survey for Current Practice in Brain Tumor Management III: Brain Metastasis and Primary Central Nervous System Lymphoma. Brain Tumor Res. Treat. 2020, 8, 20-28. [CrossRef]

20. Lin, N.U.; Lee, E.Q.; Aoyama, H.; Barani, I.J.; Barboriak, D.P.; Baumert, B.G.; Bendszus, M.; Brown, P.D.; Camidge, D.R.; Chang, S.M.; et al. Response Assessment Criteria for Brain Metastases: Proposal from the RANO Group. Lancet Oncol. 2015, 16, e270-e278. [CrossRef]

21. Sperduto, P.W.; Berkey, B.; Gaspar, L.E.; Mehta, M.; Curran, W. A New Prognostic Index and Comparison to Three Other Indices for Patients With Brain Metastases: An Analysis of 1,960 Patients in the RTOG Database. Int. J. Radiat. Oncol. 2008, 70, 510-514. [CrossRef] [PubMed]

22. Sperduto, P.W.; Jiang, W.; Brown, P.D.; Braunstein, S.; Sneed, P.; Wattson, D.A.; Shih, H.A.; Bangdiwala, A.; Shanley, R.; Lockney, N.A.; et al. Estimating Survival in Melanoma Patients With Brain Metastases: An Update of the Graded Prognostic Assessment for Melanoma Using Molecular Markers (Melanoma-MolGPA). Int. J. Radiat. Oncol. 2017, 99, 812-816. [CrossRef] [PubMed]

23. Sperduto, P.W.; Yang, T.J.; Beal, K.; Pan, H.; Brown, P.D.; Bangdiwala, A.; Shanley, R.; Yeh, N.; Gaspar, L.E.; Braunstein, S.; et al Estimating Survival in Patients With Lung Cancer and Brain Metastases: An Update of the Graded Prognostic Assessment for Lung Cancer Using Molecular Markers (Lung-MolGPA). JAMA Oncol. 2017, 3, 827-831. [CrossRef] [PubMed]

24. Lee, S.R.; Roh, T.H.; Jeong, D.H.; You, N.; Jang, A.H.; Seo, M.R.; Choung, J.H.; Park, B.; Kim, S.-H. A Simple and Practical Scoring System for Radiosurgical Treatment in Patients with Brain Metastases. Stereotact. Funct. Neurosurg. 2020, 98, 278-285. [CrossRef] [PubMed]

25. Roh, T.H.; Choi, M.S.; You, N.; Jeong, D.; Jang, A.H.; Seo, M.R.; Lee, S.R.; Kim, S.-H. Identifying Candidates for Gamma Knife Radiosurgery among Elderly Patients with Brain Metastases. J. Neurooncol. 2018, 137, 559-565. [CrossRef]

26. Gaspar, L.; Scott, C.; Rotman, M.; Asbell, S.; Phillips, T.; Wasserman, T.; McKenna, W.G.; Byhardt, R. Recursive Partitioning Analysis (RPA) of Prognostic Factors in Three Radiation Therapy Oncology Group (RTOG) Brain Metastases Trials. Int. J. Radiat. Oncol. Biol. Phys. 1997, 37, 745-751. [CrossRef]

27. Kalkanis, S.N.; Kondziolka, D.; Gaspar, L.E.; Burri, S.H.; Asher, A.L.; Cobbs, C.S.; Ammirati, M.; Robinson, P.D.; Andrews, D.W.; Loeffler, J.S.; et al. The Role of Surgical Resection in the Management of Newly Diagnosed Brain Metastases: A Systematic Review and Evidence-Based Clinical Practice Guideline. J. Neurooncol. 2010, 96, 33-43. [CrossRef]

28. Nieder, C.; Mehta, M.P. Prognostic Indices for Brain Metastases-Usefulness and Challenges. Radiat. Oncol. 2009, 4, 10. [CrossRef]

29. Weltman, E.; Salvajoli, J.V.; Brandt, R.A.; de Morais Hanriot, R.; Prisco, F.E.; Cruz, J.C.; de Oliveira Borges, S.R.; Wajsbrot, D.B. Radiosurgery for Brain Metastases: A Score Index for Predicting Prognosis. Int. J. Radiat. Oncol. 2000, 46, 1155-1161. [CrossRef]

30. El Shafie, R.A.; Dresel, T.; Weber, D.; Schmitt, D.; Lang, K.; König, L.; Höne, S.; Forster, T.; von Nettelbladt, B.; Eichkorn, T.; et al. Stereotactic Cavity Irradiation or Whole-Brain Radiotherapy Following Brain Metastases Resection-Outcome, Prognostic Factors, and Recurrence Patterns. Front. Oncol. 2020, 10, 693. [CrossRef]

31. McPherson, C.M.; Suki, D.; Feiz-Erfan, I.; Mahajan, A.; Chang, E.; Sawaya, R.; Lang, F.F. Adjuvant Whole-Brain Radiation Therapy after Surgical Resection of Single Brain Metastases. Neuro-Oncology 2010, 12, 711-719. [CrossRef]

32. Stelzer, K.J. Epidemiology and Prognosis of Brain Metastases. Surg. Neurol. Int. 2013, 4, S192-S202. [CrossRef]

33. Erickson, A.W.; Das, S. The Impact of Targeted Therapy on Intracranial Metastatic Disease Incidence and Survival. Front. Oncol. 2019, 9, 797. [CrossRef]

34. Tonse, R.; Tom, M.C.; Mehta, M.P.; Ahluwalia, M.S.; Kotecha, R. Integration of Systemic Therapy and Stereotactic Radiosurgery for Brain Metastases. Cancers 2021, 13, 3682. [CrossRef]

35. Ahn, B.-C.; Kim, J.H.; Pyo, K.-H.; Lim, S.M.; Hong, M.H.; Kim, H.R.; Cho, B.C. Analyses of CNS Response to Osimertinib in Patients with T790M-Positive Advanced NSCLC from ASTRIS Korean Subset, Open-Label Real-World Study. Cancers 2021, 13, 3681. [CrossRef]

36. Yang, S.-H.; Kim, H.Y.; Lee, S.; Jin, S.J. The Effect of Epidermal Growth Factor Receptor Mutation on Intracranial Progression-Free Survival of Non-Small Cell Lung Cancer Patients with Brain Metastasis Underwent Gamma Knife Radiosurgery. Brain Tumor Res. Treat. 2020, 8, 103-108. [CrossRef] 
37. Colclough, N.; Chen, K.; Johnström, P.; Strittmatter, N.; Yan, Y.; Wrigley, G.L.; Schou, M.; Goodwin, R.; Varnäs, K.; Adua, S.J.; et al. Preclinical Comparison of the Blood-Brain Barrier Permeability of Osimertinib with Other EGFR TKIs. Clin. Cancer Res. 2021, 27, 189-201. [CrossRef] [PubMed]

38. Brown, P.D.; Ballman, K.V.; Cerhan, J.H.; Anderson, S.K.; Carrero, X.W.; Whitton, A.C.; Greenspoon, J.; Parney, I.F.; Laack, N.N.I.; Ashman, J.B.; et al. Postoperative Stereotactic Radiosurgery Compared with Whole Brain Radiotherapy for Resected Metastatic Brain Disease (NCCTG N107C/CEC·3): A Multicentre, Randomised, Controlled, Phase 3 Trial. Lancet Oncol. 2017, 18, 1049-1060. [CrossRef]

39. Soffietti, R.; Kocher, M.; Abacioglu, U.M.; Villa, S.; Fauchon, F.; Baumert, B.G.; Fariselli, L.; Tzuk-Shina, T.; Kortmann, R.-D.; Carrie, C.; et al. A European Organisation for Research and Treatment of Cancer Phase III Trial of Adjuvant Whole-Brain Radiotherapy Versus Observation in Patients With One to Three Brain Metastases From Solid Tumors After Surgical Resection or Radiosurgery: Quality-of-Life Results. J. Clin. Oncol. 2013, 31, 65-72. [CrossRef] [PubMed]

40. Mahajan, A.; Ahmed, S.; McAleer, M.F.; Weinberg, J.S.; Li, J.; Brown, P.; Settle, S.; Prabhu, S.S.; Lang, F.F.; Levine, N.; et al. Post-Operative Stereotactic Radiosurgery versus Observation for Completely Resected Brain Metastases: A Single-Centre, Randomised, Controlled, Phase 3 Trial. Lancet Oncol. 2017, 18, 1040-1048. [CrossRef]

41. Zhen, J.; Wen, L.; Lai, M.; Zhou, Z.; Shan, C.; Li, S.; Lin, T.; Wu, J.; Wang, W.; Xu, S.; et al. Whole Brain Radiotherapy (WBRT) for Leptomeningeal Metastasis from NSCLC in the Era of Targeted Therapy: A Retrospective Study. Radiat. Oncol. 2020, 15, 185. [CrossRef] [PubMed]

42. Lee, S.; Ahn, H.K.; Park, Y.H.; Nam, D.H.; Lee, J.I.; Park, W.; Choi, D.H.; Huh, S.J.; Park, K.T.; Ahn, J.S.; et al. Leptomeningeal Metastases from Breast Cancer: Intrinsic Subtypes May Affect Unique Clinical Manifestations. Breast Cancer Res. Treat. 2011, 129, 809-817. [CrossRef] [PubMed]

43. Lee, J.; Choi, Y.L.; Han, J.; Park, S.; Jung, H.A.; Su, J.-M.; Lee, S.-H.; Ahn, J.S.; Park, K.; Ahn, M.-J. Osimertinib Improves Overall Survival in Patients With EGFR-Mutated NSCLC With Leptomeningeal Metastases Regardless of T790M Mutational Status. J. Thorac. Oncol. 2020, 15, 1758-1766. [CrossRef] [PubMed]

44. Liao, B.-C.; Lee, J.-H.; Lin, C.-C.; Chen, Y.-F.; Chang, C.-H.; Ho, C.-C.; Shih, J.-Y.; Yu, C.-J.; Yang, J.C.-H. Epidermal Growth Factor Receptor Tyrosine Kinase Inhibitors for Non-Small-Cell Lung Cancer Patients with Leptomeningeal Carcinomatosis. J. Thorac. Oncol. 2015, 10, 1754-1761. [CrossRef] [PubMed]

45. Baliga, S.; Garg, M.K.; Fox, J.; Kalnicki, S.; Lasala, P.A.; Welch, M.R.; Tomé, W.A.; Ohri, N. Fractionated Stereotactic Radiation Therapy for Brain Metastases: A Systematic Review with Tumour Control Probability Modelling. Br. J. Radiol. 2017, 90, 20160666. [CrossRef]

46. Soltys, S.G.; Adler, J.R.; Lipani, J.D.; Jackson, P.S.; Choi, C.Y.H.; Puataweepong, P.; White, S.; Gibbs, I.C.; Chang, S.D. Stereotactic Radiosurgery of the Postoperative Resection Cavity for Brain Metastases. Int. J. Radiat. Oncol. 2008, 70, 187-193. [CrossRef]

47. Choi, C.Y.H.; Chang, S.D.; Gibbs, I.C.; Adler, J.R.; Harsh IV, G.R.; Lieberson, R.E.; Soltys, S.G. Stereotactic Radiosurgery of the Postoperative Resection Cavity for Brain Metastases: Prospective Evaluation of Target Margin on Tumor Control. Int. J. Radiat. Oncol. 2012, 84, 336-342. [CrossRef] 